\title{
SIGNO Y LENGUAJE EN SAN AGUSTIN
}

MaURicio BeUchot

INSTITUTO de InVEstigaciones Filosóficas

Universidad Nacional Autónoma de Méxio

\section{Introducción}

Ludwig Wittgenstein comienza sus Investigaciones Filosóficas con una cita de San Agustín en la que éste expone su teoría de la adquisición del lenguaje. Conviene completar la filosofía del lenguaje de este medieval para captar en ella por qué Wittgenstein le dio tanta importancia. En verdad, Agustín estudió mucho el signo y el lenguaje; atribuye a las disciplinas sermocinales o lingüísticas (gramática, dialéctica y retórica) la capacidad de producir un conocimiento del signo y del lenguaje que nos habilita para manejar con propiedad los instrumentos de nuestra comunicación. Tal conocimiento alcanza su plenitud en la retórica, que es ciencia y arte del bien decir. De ella dice: "[el hombre] ama [la ciencia o arte del decir] porque conoce e intuye en las razones del ser la belleza de la ciencia, en la que se contienen las nociones de todos los signos, y la utilidad de un arte que hace posible a los hombres comunicar entre sí sus pensamientos, para que la sociedad humana no sea algo peor que la soledad estéril, como sucedería de no poder comunicarse los hombres sus ideas por medio del lenguaje". 1

El estudio del signo (semiótica), y en especial el del signo lingüistico (filosofía del lenguaje), obtiene un lugar privilegiado en la filosoffa de San Agustín. ${ }^{2}$ Signo y lenguaje son dos de sus principales preocupaciones, dado que es para él algo muy importante el tema de la enseñanza. $\mathrm{Y}$ ambos son necesarios para enseñar, aun cuando la enseñanza se alcanza

1 S. Agustín, De trinitate, 1. X, c. 1, n. 2; ed. bilingüe de L. Arias, Madrid: BAC, 1956 ( $2^{\mathrm{a}}$ ed.), p. 577.

2 Sobre aspectos generales de San Agustín, cfr. E. Gilson, Introduction à l'étude de Saint Augustin, Paris: Vrin, 1949 ( ${ }^{a}$ ed.); sobre su filosofía, cfr. J. Pegueroles, El pensamiento filosófico de San Agustín, Barcelona: Labor, 1972; sobre su semiótica y su filosofía del lenguaje en general, cfr. U. Wienbruch, "'Signum', 'Significatio' und 'Illuminatio' bei Augustin", en A. Zimmermann (ed.), Der Begriff der Repraesen. tatio im Mittelalter. Stellvertretung, Symbol, Zeichen, Berlin-Nueva York: Walter de Gruyter, 1971, pp. 76-93. 
suficientemente no en los signos y palabras exteriores, sino sobre todo cuando se recibe en el interior de la persona, en su mente.

Muchos pasajes del genio de Hipona nos brindan ciertos lineamientos de semiótica y de filosoffa del lenguaje, ampliamente tomadas. Trataremos de recoger sus enseñanzas más básicas sobre el signo y el lenguaje. Ciertamente habría que conectarlas con otras teorías suyas sobre el conocimiento y sobre el ser (gnoseología y ontologia), pero creemos que para el objetivo que nos hemos propuesto bastarán las pocas anotaciones que sobre eso hagamos. Lo principal será recoger sus definiciones y divisiones de los signos, sus ideas acerca de las conexiones entre los signos mismos y las de éstos con la realidad, principalmente en lo que se refiere al signo lingüfstico, al lenguaje.

\section{Definiciones y divisiones principales del signo}

Agustín parece tener clara la importancia de los signos en la vida humana. Todos los seres se dividen en signos y significables, nos dice en el De magistro, pues todos los signos son cosas, aunque no todas las cosas sean signos, sino que hay además "significables", como añade en el $D e$ doctrina christiana. Los signos son, pues, cosas de cierto tipo especial. Eso que tienen de especial es que son cosas que se usan para significar; y el significar (o representar) tiene como principal cometido enseñar a los demás. En definitiva, todo comunicar es enseñar, pues al preguntar enseñamos lo que deseamos saber, y al responder enseñamos lo que pensamos que satisface el deseo del otro. En todo ello se cumple la comunicación, para la cual sirven los signos. Aunque en la Edad Media se llegaba a considerar todo el universo creado como un signo de Dios, Agustín no reduce todo al signo, sino que - como hemos visto- habla de signos y significables, y nos habla de la representación como lo propio de los signos.

Los signos tienen definición y división. Agustín se dedica a examinarlos. La definición que hizo famosa aparece en el De doctrina christiana, y dice asi: "el signo, en efecto, es la cosa que, además de la especie [o imagen, o representación] que introduce en los sentidos, hace llegar al pensamiento de otra cosa distinta". ${ }^{3}$ Los ejemplos que da abarcan tanto signos naturales como signos artificiales o convencionales. Naturales, como la huella; además de ver la huella o tener su representación en los sentidos, llegamos al pensamiento del animal que pasó. También es signo natural el humo, ya que representa naturalmente al fuego. Los signos artificiales tienen como prototipo más convencional el lenguaje, y así

s S. Agustin, De doctrina christiana, 1. II, c. 1, n. 1; ed. J. P. Migne, Paris: Patrologia Latina, 1865, vol. 34, col. 35. 
Agustín propone como ejemplo la voz, por la cual llegamos al conocimiento de las afecciones del ánimo del que la usa. $\mathrm{Y}$ también convencional es la trompeta, ya que a los soldados les puede significar y ordenar diferentes cosas con la distinta modulación de su sonido. ${ }^{4}$

La división del signo que establece San Agustín es bimembre: unos son los signos naturales y otros los artificiales o "dados" (signa data); ambos han aparecido en los ejemplos que aduce después de la definición. Añade también la definición de cada una de estas clases de signos de su clasificación: "[Signos] naturales son los que, sin voluntad y sin ningún deseo de que signifiquen, además de si mismos hacen conocer algo distinto de ellos, como lo hace el humo, que significa el fuego." 5 Esta definición del signo natural aporta algo a la definición general del signo. Claramente se ve que añade el constitutivo diferencial o especificante del signo natural por el que se distingue del artificial o convencional, a saber, el no haber sido impuesto por la voluntad humana según algún deseo de significar; pues, en efecto, han sido establecidos, "instituidos" o "impuestos" por la misma naturaleza. Agustín aclara que no le interesan tanto los signos naturales cuanto los artificiales o convencionales, en los cuales se centrará. La definición que da de ellos es así: "los signos dados, en cambio, son los que mutuamente se dan los vivientes para manifestar, en cuanto pueden, los movimientos de su alma, o cualesquier cosas que sienten o entienden". ${ }^{6}$ Ya que son los que introduce el deseo, pertenecen a aquellos que tienen deseo, a saber, los animales, tanto irracionales como racionales. Se usan para transmitir los contenidos anímicos del alma de uno al alma del otro. En los que sólo tienen alma sensitiva, como los brutos irracionales, sólo se intercambian signos de contenido sensible; los hombres, además, signos de contenido inteligible.

Asimismo, los signos humanos reciben de Agustín una división según los sentidos a los que aluden. La mayoría alude a los ofdos (es decir, las palabras del lenguaje); otros aluden a los ojos (entre ellos la escritura, que representa al lenguaje oral) y muy pocos a otros sentidos. Sin discusión, las palabras (verba) son los más importantes entre los signos humanos, pues en ellas se expresan y con ellas se comunican la mayoría de los pensamientos. ${ }^{7}$ En especial, las palabras alcanzan a cubrir ese

- Se ha discutido la definición de San Agustín por incompleta. Esto sucede ya en la escolástica medieval, pues se alega que sólo abarcaría los signos sensibles pero no los inteligibles, como los conceptos. Cfr. M. Beuchot, La filosofia del lenguaje en la Edad Media, México: UNAM, 1981, p. 14.

5 S. Agustín, De doctr. chr., 1. II, c. 1, n. 2; col. 36.

6 Ibid., c. 2, n. 3, col. 37.

7 Ibid., cols. $37-38$. 
cúmulo de cosas que no pueden darnos los demás sentidos, a saber, las cosas "abstractas".

En un capítulo del diálogo De magistro, Agustín se pregunta si es posible mostrar algo sin signos. Al principio parece decir que no, pues cuando no mostramos algo hablando, lo mostramos con gestos señalándolo a la vista, como hacen los histriones y los sordomudos. Pero alude al caso de que alguien pregunte qué es el caminar y entonces el interlocutor camine delante de él para mostrarle lo que es. En ese momento se estaría enseñando (o comunicando) sin signos, sino con la cosa misma, ya que el caminar no es signo de sí mismo; se estaría enseñando con la propia realidad, no con su signo. Sin embargo, Agustín añade que sólo se daría esto en casos muy rudimentarios. Las más de las veces hay que añadir signos. Dice: "Confieso que sin signos no podemos mostrar una cosa, si, cuando lo hacemos, se nos pregunta; pues si nada añadimos, el que pregunta pensará que no queremos enseñarle y que, despreciándolo, continuamos nuestra acción. Pero si nos pregunta de algo que podemos hacer - y no pregunta mientras lo hacemos - podemos, haciéndolo, después de su pregunta, mostrarle lo que pregunta, más con la cosa misma que con un signo: a no ser que mientras hablo me pregunte qué es hablar, pues, cualquier cosa que le diga para enseñarlo, siempre lo debo hacer hablando; por lo cual seguiré enseñándole hasta hacerle claro lo que él quiere, sin apartarme de la cosa que deseaba le enseñara, ni buscando signos, que no sean ella misma, para mostrársela." 8 Lo mismo ocurre cuando, por ejemplo, se nos pregunta dónde se encuentra algún edificio o calle, y —si está a la vista - lo señalamos; en ese caso contestamos enseñando la cosa misma, y no mediante signos. Aunque, como bien comenta Agustín, resultaría un tanto extraño sólo hacer eso, sin añadir algún signo más que dé el contexto.

\section{El lenguaje}

Encontramos preciosos desarrollos doctrinales en otras obras de San Agustín sobre el lenguaje. A partir de ellas podemos reconstruir mínimamente su filosofía del lenguaje. Acerca del origen del lenguaje nos habla en las Confessiones; sobre la relación pensamiento-lenguaje-cosas, en el De trinitate; y sobre la función y otros aspectos del mismo, en el ya mencionado De magistro. De ellos extraeremos algunos puntos de la filosofía del lenguaje de San Agustín.

Al igual que los signos, para Agustín el lenguaje tiene como objetivo

8 Idem, Del maestro, trad. J. R. Sanabria, México: UIA, 1979, p. 27. Hemos discutido con el Dr. Sanabria algunos detalles de la traducción, lo cual le agradecemos. 
enseñar o recordar. ${ }^{9}$ De hecho, enseñar y recordar son lo mismo, dada la teoría del conocimiento como recuerdo que hereda Agustín de los platónicos. $Y$ en el fondo toda la comunicación es enseñar o hacer recordar. $Y$ cuando no se habla con otro, de modo que le enseñemos o que él nos enseñe a nosotros, de todas maneras hablamos con nosotros mismos y nos hacemos recordar cosas. Es decir, la función más amplia del lenguaje es recordar (que es enseñar, aun sea a nosotros mismos): "Aunque no emitamos ningún sonido, sin embargo, en cuanto pensamos las palabras mismas, hablamos en nuestro interior; así que con la palabra no se hace otra cosa que recordar, mientras la memoria, en la que están grabadas las palabras, repasándolas, hace venir a la mente las cosas mismas de las que las palabras son signos." 10

Las palabras son signos, y éstos dicen relación principal a los significados. Por ello a Agustín le preocupa estudiar esa relación. En el diálogo De magistro — donde se estudia la injerencia del lenguaje en la enseñanza-, Agustín investiga esta relación entre signo y significado. $Y$ comienza suponiendo que todas las palabras de una proposición tienen significado. Se sitúa en una especie de atomismo lógico, parecido al de Russell en los años veinte, cuando veía la necesidad de que cada palabra de un enunciado tuviera denotación. Pero Agustín, al analizar esta tesis aplicándola a casos concretos, tropieza con dificultades que le obligan a postular diferentes tipos de significado. Dialogando con su hijo Adeodato - en esa obra_, Agustín le hace buscar el significado de cada palabra de un verso de la Eneida, pues Adeodato es el que hizo brotar esa tesis de que no hay signo sin cosa significada. Dicho verso es: "Si nihil ex tanta Superis placet urbe relinqui" (es decir: "Si nada de tan gran ciudad place a los dioses dejar"). Comenzando por la primera palabra, el 'si', se preguntan qué puede significar. $Y$ la respuesta es que no, ciertamente, alguna cosa de las que vemos a nuestro alrededor, sino que más bien significa duda, y la duda está en el alma, por lo que -concluyen- dicha expresión significa algo del alma y no algo del mundo externo. En la investigación de Agustín y Adeodato comienzan a surgir diferentes tipos de significado: unos que son cosas extramentales y otros que son cosas intramentales, como les ha hecho ver la misma palabra 'si'. Algo parecido sucede con la siguiente palabra del verso, que es 'nada'. $\mathrm{Si}$ se pensara que es signo porque significa alguna cosa como las que vemos, dejaría de ser signo, porque 'nada' no significa ninguna de las cosas que nos rodean, i.e. no designa ninguna cosa física. Para que pueda seguir siendo signo, dado el supuesto de que todo signo significa al-

9 Ibid., p. 17.

10 Ibid., p. 19.

11 Virgilio, Eneida, 1. II, v. 659. 
guna cosa, tiene que aceptarse que designa alguna cosa del alma. Podría sospecharse que tanto 'si' como 'nada' no tienen que significar sólo alguna cosa del alma, sino alguna cosa extramental pero no de carácter físico. Sin embargo, para no entorpecer la discusión, Agustín y Adeodato evitan entrar en esta cuestión, y, para poder avanzar en el diálogo, conceden que tanto 'si' como 'nada' significan cosas mentales o del alma. Según puede verse, Agustín se topa con palabras que significan cosas intramentales o psíquicas además de las más frecuentes palabras que significan cosas físicas. Ya hay cierta diferenciación entre diversos tipos de significado (por lo menos estos dos, ya que no se entró en la discusión de otro tipo de significado formado por posibles cosas reales pero no físicas, de tipo platónico).

A Agustín, un poco de paso, le llama la atención el que dos signos distintos signifiquen lo mismo. Dos expresiones sinónimas designan la misma cosa, aun siendo expresiones diferentes. Agustín dice: "Busco no sé qué de idéntico y uno que esos dos [vocablos] significan." ${ }^{12}$ Roza el tema del sentido y la referencia como justificación de ese hecho (según lo yio después Frege): dos expresiones con distinto sentido o modo de expresión pueden tener en común la misma referencia, como algo "idéntico y uno" a lo que designan.

Pasa Agustín a examinar las relaciones de significación que pueden tener los signos con los signos, ya que además de designar cosas con los signos podemos designar otros signos (tal vez en cuanto que también son cosas, además de ser signos). Es el problema de explicar el fenómeno del metalenguaje (como se dice actualmente). De un signo o de un conjunto de signos o de todo un lenguaje podemos hablar mediante un lenguaje de orden superior - superior por el hecho de que se refiere a ese lenguaje del que habla y al que tiene como inferior. El lenguaje del que se habla recibe el nombre de "lenguaje-objeto" y al lenguaje con el que se habla se le denomina "meta-lenguaje". Ya los escolásticos medievales, posteriores a San Agustín, hablaban de un "modo formal" y de un "modo material" del lenguaje (suppositio formalis y suppositio materialis). El formal es el uso ordinario de una palabra, i.e. el objeto-lingüístico, por ejemplo "hombre", al decir "el hombre es mortal", tenía ese uso; y el segundo era un uso especial, por el que la palabra se refería a sí misma como expresión y a las de su misma forma (homoiomorfas, una como type o paradigma y otras como tokens o especímenes), i.e. adquiría un nivel metalingüístico; por ejemplo "hombre" en "hombre' es bisílabo" o en " 'hombre' es un sustantivo". Es lo que después se distinguirá como el uso de una palabra y la mención de la misma.

12 S. Agustín, Del maestro, p. 22. 
En "el hombre es mortal" yo uso la palabra "hombre" y en " 'hombre' es bisílabo" yo menciono la palabra "hombre".13 San Agustín hace algunas exploraciones de esta referencia de los signos por los signos mismos - de nivel metalingüístico y objetolingüístico- Veremos dos de ellas: la de los signos que se significan a sí mismos, o reflexivos, y la de los signos que se significan mutuamente, o reciprocos.

\section{Signos reflexivos o autorreferentes}

Lo primero que en este orden encuentra Agustín es que se puede hablar de las palabras con ellas mismas, por ejemplo "nombre" se puede designar a sí mismo, y además " 'nombre' es un nombre" es correcto. Parte de esos supuestos para indicar cómo se muestran los signos. Ello puede ser o con signos de la misma clase, por ejemplo signos audibles (voces) con otros signos audibles (también voces); o con signos de diferente clase, como signos audibles (voces) con signos visibles (letras). La palabra "nombre" significa nombres (tales como "Rómulo", "Roma", "virtud", "río", etc.); por lo tanto, el nombre significa nombres, o se significa a sí mismo (es autopredicativo o autorreferencial; "no-heterólogo", como diría Russell). Y además todo nombre es palabra, y toda palabra es signo; por lo tanto, hay signos que se significan a sí mismos. Agustín lo especifica: “¿Acaso no sucede esto con 'nombre' ('nomen')? Ya que él significa los nombres de todos los géneros y él mismo ('nomen') es un nombre del género neutro. Porque si te preguntara qué parte de la oración es 'nombre' ('nomen'), no podrías responderme acertadamente sino diciendo que es un nombre. [...] Por lo tanto, hay signos que, entre otras cosas que significan, se significan a si mismos".14

\section{Signos reciprocos o mutuamente significativos}

Agustín pasa a los signos que se refieren a otros signos (además de referirse a sí mismos); y esos otros signos a los que se refieren pueden a su vez referirse a los primeros. Es decir, habla ahora de los signos que, además de ser reflexivos, son recíprocos. Pues a veces un signo que significa a otro es a su vez significado por este último, pero a veces no hay esa equivalencia. Hay esa equivalencia algunas veces: "Tienen el mismo valor 'palabra' en general y 'nombre' en general. En efecto, el razonamiento nos enseñó que todas las partes de la oración también son nombres porque se les pueden añadir pronombres, y de todas se puede decir 
que nombran algo y no hay ninguna que, si se le añade un verbo, no pueda formar una proposición simple." 15

Pero en esta identificación de palabra y nombre, cuando Agustín dice que todas las palabras o partes de la oración también son nombres, labora sobre un equívoco. Se confunde lo objeto-lingüístico con lo metalingǘrstico. Pues el procedimiento del de Hipóna es presentar dos oraciones completas: "me agrada el si" y "me desagrada el porque", en las que 'si' y 'porque', en lugar de actuar como conjunciones, actúan como nombres, ya que si se toman metalingüísticamente (o con suposición material, o en mención meta-lingüística y no en uso objeto-lingüístico), con ello se convierten en nombres y dejan de ser conjunciones, debido a una situación nueva y especial, pero no porque de suyo sean nombres. Sabido es que toda palabra, sea el categoremático o sincategoremático que se quiera, se convierte en nombre al ponérsela como sujeto de una oración en la que dicha palabra adquiere la suposición material, ya que se trata entonces de una oración metalingüistica.

Sintaxis: elementos y compuestos enunciativos

Las palabras son signos, y se concatenan formando oraciones. $\mathrm{La}$ sintaxis tiene precisamente - como en los gramáticos antiguos- esa función de establecer el léxico y la gramática. Por el léxico tenemos los elementos o partes de la oración; por la gramática obtenemos con ellos enunciados bien formados. Para Agustín, la palabra es "lo que se profiere con la articulación de la voz y tiene significado".16 Es la palabra, pues, una voz significativa (por artificio o convención, dado que no pertenece a los signos naturales) y articulada (por eso se puede poner en letras de escritura). Se distingue de la voz inarticulada, que, aun cuando sea voz significativa, no es palabra, sino grito, gemido, u otra cosa por el estilo. Aunque no usa esta nomenclatura, la división que introduce Agustin entre las palabras es principalmente la que en etapa posterior las partirá en categoremáticas y sincategoremáticas (i.e. las que significan por sí solas y las que significan por acompañar a las otras).

Las categoremáticas incluyen nombres y verbos, los cuales son mencionados explícitamente por Agustín: "Pues enseñan los más famosos maestros en dialéctica que una oración completa, ya afirmativa, ya negativa, consta de nombre y de verbo; a esta clase de frases el mismo Tulio, en un pasaje, llama enunciación." ${ }^{17}$ A través de Cicerón, el de Hipona re-

16 Ibid., p. 45.

16 Ibid., p. 31 .

17 Ibid., p. 40. 
cupera la tradición gramática latina, en la que la sintaxis tenía esas reglas tan precisas para formar oraciones o enunciados.

El nombre era visto como sujeto por excelencia y el verbo como predicado por la excelencia. Esto corresponde a lo que actualmente Strawson ve como el carácter incompleto o no-saturado del predicado y el completo o saturado (de sentido) del sujeto. Agustín lo expresa así en su diálogo:

Agustín.-¿Ves que en cada enunciación hay un nombre: en la primera, 'hombre'; en la segunda, 'caballo'? ¿Ves que cada una tiene verbo: 'está sentado' y 'corre'?

Adeodato.-Lo veo.

Agustín.-Luego si sólo dijera: 'está sentado', o 'corre', con razón me preguntarías quién o qué cosa, para que te respondiera: 'hombre', o 'caballo', o 'animal', o cualquier otra cosa, para que el nombre referido al verbo pueda completar la enunciación, es decir, aquella proposición que pueda ser afirmativa o negativa. ${ }^{18}$

En cuanto a los demás elementos sintácticos de la oración, los sincategoremáticos son los que en la lengua latina se utilizan para complementar y unirse al nombre y al verbo.

Semántica: relación entre palabras y cosas o entre signos y significables

Las palabras o signos lingüísticos, y los signos en general, son únicamente medios para llegar a las cosas significadas, que son los fines de éstos. "[Si se] pregunta qué es el hombre, por esa regla del lenguaje ya convenida, el espíritu se iría a lo significado por aquellas dos sílabas y no se respondería otra cosa que 'animal' o también se daría la definición completa, es decir, 'animal racional mortal'." 19 O sea que los signos palidecen para dejar brillar a las cosas a las que remiten, porque todo lo que es en vistas a otra cosa necesariamente está supeditado a ella y vale menos que ella.

Pero ¿cómo aprendemos a ir a los significados a partir de los signos? Aquí se sitúa la teoría agustiniana de la adquisición del lenguaje, que se encuentra de manera paradigmática en las Confessiones. Narra el mismo Agustín su propia experiencia y recuerda cómo fue que aprendió a hablar: "Ciertamente no me enseñaron esto los mayores, presentándome las palabras con cierto orden de método, como luego después me enseñaron las letras; sino yo mismo con el entendimiento que tú me dis- 
te, Dios mío, al querer manifestar mis sentimientos con gemidos y voces varias y diversos movimientos de los miembros, a fin de que satisficiesen mis deseos, y ver que no podía todo lo que yo -quería ni a todos los que yo quería." ${ }^{20} \mathrm{Y}$ añade el famoso párrafo que recoge Wittgenstein al comienzo de sus Philosophische Untersuchungen y al que, a pesar de atacarlo, da tanta importancia: "Así pues, cuando éstos [i.e. los mayores] nombraban alguna cosa, fijábala yo en la memoria, y si al pronunciar de nuevo tal palabra movían el cuerpo hacia tal objeto, entendía y colegia que aquel objeto era el denominado con la palabra que pronunciaban, cuando lo querían mostrar. Que ésta fuese su intención deducíalo yo de los movimientos del cuerpo, que son como las palabras naturales de todas las gentes, y que se hacen con el rostro y el guiño de los ojos y cierta actitud de los miembros y tono de la voz, que indican los afectos del alma para pedir, retener, rechazar o huir alguna cosa. De este modo, de las palabras, puestas en varias frases y en sus lugares y oídas repetidas veces, iba coligiendo yo poco a poco los objetos que significaban y, vencida la dificultad de mi lengua, comencé a dar a enten. der mis quereres por medio de ellas." ${ }^{21}$

Según puede verse, de acuerdo a esta teoria, se aprende por la asociación de la palabra a la cosa, lo cual se aprende por ostensión; es decir, se pronuncia el signo y se hace la ostensión (o se busca la ostensión) del objeto, se muestra: "Para que entiendas más claramente esto, supón que oímos por primera vez decir 'cabeza' y no sabiendo si esta palabra sea sólo un sonido o también signifique algo, preguntamos qué es cabeza (recuerda que queremos tener noticia no de la cosa significada sino del mismo signo, conocimiento que ciertamente no tenemos mientras ignoramos de qué es signo): si pues cuando hacemos tal pregunta se nos muestra con el dedo la cosa misma, al verla, aprendemos el signo que sólo habíamos oído, pero no habíamos entendido. Pero como en tal signo hay dos cosas, el sonido y el significado, ciertamente no percibimos el sonido mediante el signo, sino mediante la simple percusión del oído; y percibimos el significado por la visión de la cosa significada. Porque apuntar con el dedo no puede significar más que aquello a lo que el dedo apunta, y apunta no al signo sino al miembro del cuerpo que llamamos "cabeza'." 22

Pero no basta el mero conocimiento de los signos para conocer los sig-

20 Idem, Confessiones, 1. I, c. 8, n. 13; ed. bilingüe de A. C. Vega, Madrid: BAC, 1946, p. 337.

21 Ibid., p. 339. Para los comentarios que sobre este pasaje hace Wittgenstein, véase Philosophische Unitersuchungen, Frankfurt am Main: Suhrkamp Verlag, 1967, I, 1, p. 13.

22 S. Agustín, Del maestro, pp. 62-63. Cfr. también De trinitate, 1. X, c. 1, n. 2 , p. 575 . 
nificados: hace falta la intervención iluminadora del pensamiento. Simplemente, si no recordamos por la memoria a qué cosa se asocia el signo, en manera alguna podemos aprender el lenguaje. Es necesaria, pues, la intervención del pensamiento.

\section{Pensamiento y lenguaje}

Para San Agustin, entre el signo y la cosa designada (significado o significable) media el pensamiento. Este ocupa un lugar mediador entre el lenguaje y la cosa, hace que el signo pueda designar a la cosa o referirse a ella. Tal mediación consiste - de manera cercana a Aristóteles- ${ }^{23}$ en que el concepto mental del pensamiento es lo que directamente significa la palabra y, a través de él y de manera indirecta, la palabra significa de modo principal aunque mediato al objeto significado. Además, el concepto mental o del pensamiento puede llamarse "palabra interior" o "verbo interior" en un sentido particular: "Se llama 'verbo' el sonido articulado silábicamente en el espacio y en el tiempo, ora lo modulen nuestros labios, ora quede recatado en nuestro pensar. En otro sentido es verbo todo lo conocido e impreso en el alma mientras lo retenga la memoria..." ${ }^{24}$ Incluso puede decirse que el signo principal de la cosa es el concepto, no la voz — según San Agustín-, y que cuando expresamos palabras orales o escritas, i.e. externas, lo que en realidad intentamos es transmitir al otro nuestra palabra interior, que es el concepto. Este es el que realmente pretendemos inculcar a nuestro interlocutor, y lo revestimos de un ropaje sonoro, o de otro tipo de material, a fin de revelar exteriormente lo que habita nuestro interior psíquico: "Y cuando dirigimos la palabra a otros, añadimos a nuestro verbo interior el ministerio de la voz o algún otro signo sensible, a fin de producir en el alma del que escucha, mediante un recuerdo material, algo muy semejante a lo que en el alma del locutor permanece. Así, nada hacemos por los miembros del cuerpo, ni en palabras ni en obras, al aprobar o reprender la conducta moral de los hombres, sin que se anticipe en nuestro interior el verbo secreto. Nadie queriendo hace algo sin antes hablarlo en su corazón." 25

Otro rasgo de la mediación que ejerce el pensamiento entre lenguaje

23 Cfr. M. Beuchot, "El pensamiento y su relación con el lenguaje", en Critica, $\mathrm{XVI} / 46$ (1984), pp. 47-59, recogido posteriormente en Idem, Ensayos marginales sobre Aristoteles, México: Centro de Estudios Clásicos del Instituto de Investigaciones Filológicas, UNAM, 1985.

24 S. Agustin, De trin., 1. IX, c. 10, n. 15, p. 563. Para la doctrina agustiniana anterior sobre este tema, cfr. D. W. Johnson, "Verbum in the early Augustine (386397)", en Recherches Augustiniennes, 8 (1972), pp. 25-53.

25 S. Agustin, De trin., 1. IX, c. 7, n. 12, p. 559. 
y cosa es que el pensamiento causa al lenguaje, en un sentido muy peculiar; es decir, el pensamiento es la condición sine qua non del lenguaje; no hay palabra si antes no hay un concepto que la apoye -en el sentido de darle significación: "...el verbo [o palabra] sin el pensamiento no puede existir (pensamos cuanto decimos, aunque se trata del verbo interior, que no pertenece a ningún idioma)..." 26 Esto resulta algo difícil de comprender para nosotros, lectores modernos de Agustín, habituados a la tesis actual de que no hay pensamiento sin lenguaje, y que, por lo tanto, no habría esa palabra interna anterior a cualquier idioma, la cual sería el concepto del pensamiento, un lenguaje mental. Si es anterior a cualquier idioma, es idéntico en todos los seres humanos a pesar de la diversidad de lenguas y, por lo tanto, objetivo, como ya lo véa Aristóteles. De él se desprende la tesis de que con el lenguaje significamos primeramente las cosas tal como las pensamos y después (y secundariamente o derivativamente) tal como existen en la realidad, ya que captamos su ser por el pensamiento. Agustín lo expresa así: "Hablamos, por consiguiente, de las cosas conocidas en las que pensamos, cosas que nos son conocidas aun cuando no pensemos en ellas. Mas si queremos mencionarlas, sólo pensando es posible, porque, aunque las palabras no resuenen fuera, el que piensa habla siempre en su corazón." ${ }^{27}$

$\mathrm{Y}$ esta palabra interior no pertenece a ningún idioma, es anterior a cualquier lengua, es el mismo pensamiento, al cual por cierta translación se le puede llamar "lenguaje", es decir "lenguaje mental" o "lenguaje interior", al modo como al concepto del pensamiento se le puede también llamar "palabra", o sea, "palabra mental" o "verbo interior". La palabra mental o interior es la que en verdad hace significativa a la palabra exterior, la hace signo porque la dota de significado al darle un contenido sígnico, una significación o un sentido. Gracias a ese sentido que la palabra exterior recibe del concepto o palabra interior es como puede referirse al objeto, denotarlo. Esta situación teórica constituye, para Agustín, una prueba de la función que ha asignado al pensamiento, intermediario entre la palabra y la cosa. Resulta, así, la única explicación aceptable para Agustín del fenómeno de significado: "Es, pues, necesario, cuando decimos verdad, esto es, cuando decimos lo que sabemos, que nuestro verbo nazca de la ciencia atesorada en nuestra memoria y sea en absoluto idéntico a la naturaleza de la ciencia de la cual nace. Informado el pensamiento por la realidad conocida, es verbo lo que decimos en nuestro corazón, verbo que no es griego, ni latino, ni pertenece a idioma alguno; pero'siendo preciso hacerlo llegar a conocimiento 
de aquellos con quienes hablamos, se emplea un signo que lo exprese. Con frecuencia es un sonido, alguna vez una seña; aquél habla al ofdo, ésta a la vista; y estos signos materiales son medios que sirven para dar a conocer a los sentidos del cuerpo nuestro verbo mental. [...] Mas estos signos corporales hieren los oídos o la retina de los presentes con quienes hablamos; para comunicarnos con los ausentes se inventó la escritura; pero las letras signo son de las voces, mientras las palabras son, en nuestro lenguaje, signos del pensamiento." 28

Por consiguiente, las palabras son signos directos de los conceptos o "palabras mentales", y los conceptos son signos directos de las cosas. Todos captamos conceptualmente las cosas de una manera idéntica, que salvaguarda la objetividad del conocer, y las expresamos de manera distinta, traduciendo la palabra mental a los diversos idiomas. La tesis de fondo profesada por Agustín es que el concepto o palabra interior es signo de la cosa, y la palabra exterior es signo de la interior, mediante la cual es también signo de la cosa: "Es, pues, necesario llegar al verbo humano, al verbo del animal racional, al verbo imagen de Dios, no nacido de Él, sino hecho a su imagen, que no es sonido prolaticio ni imaginable como sonido, el cual es menester pertenezca a un idioma cualquiera, sino que es anterior a todos los signos que le representan y es engendrado por la ciencia, que permanece en el ánimo, cuando esta ciencia, tal cual es, se expresa en una palabra interior. Muy parecida a la visión de la ciencia es la visión del pensamiento. Porque, cuando se expresa por medio de un sonido o mediante un signo corpóreo, no se representa ya como es, sino tal como se la ve o se la oye por los sentidos del cuerpo." ${ }^{29}$ De esta manera, en San Agustín se hace presente - tal vez por tradición directa, tal vez por tradición indirecta a través de los neoplatónicos- la doctrina aristotélica de la relación mediadora que establece el pensamiento como puente entre el lenguaje y las cosas significadas. Ciertamente no es la misma doctrina exactamente que encontramos en Aristóteles, y se nota mucha influencia del neoplatonismo, pero contiene ese núcleo consistente en la tesis que asevera que el lenguaje es signo directo del pensamiento y éste lo es de las cosas; de modo que el lenguaje significa directamente el concepto (o la cosa tal como es concebida) e indirectamente significa la cosa designada, justamente por la mediación del concepto. Tiene, por ello, el pensamiento un papel mediador entre lenguaje y realidad. 


\section{Conclusión}

En esta exposición sucinta de la semiótica y la filosofía del lenguaje de San Agustín encontramos algunos ingredientes que pasarán a formar parte del acervo de la filosofía medieval, tanto para ser aceptados como para ser atacados o por lo menos sometidos a discusión. Su noción de signo, que se hace clásica, será las más de las veces objetada por incompleta o por lo menos modificada para que abarque no únicamente los signos sensibles, sino también los inteligibles. Su noción de lenguaje interior, del pensamiento como vinculador entre lenguaje y realidad (y como signo él mismo, lo cual parece contradictorio con su discutida definición del signo del De doctrina christiana, ya que el concepto del pensamiento será precisamente un signo intelectivo o mental y no meramente sensorial como parece indicar la definición aludida), esta conexión entre lenguaje-pensamiento-realidad será algo que (junto con la versión aristotélica de esta relación) recibirá diversas modificaciones y adaptaciones en los ạutores escolásticos, pero será una doctrina integrada al cúmulo de teorías semiótico-lingüísticas de la posteridad, si no como algo aceptado totalmente, sí como problema candente e inevitable, siempre vivo. 